\title{
Can components of the plasminogen activation system predict the outcome of kidney transplants?
}

\author{
JERZY JANKUN, OMAR A. KHAN, HESHAM I. MOSTAFA, PUNEET SINDHWANI, \\ EWA SKRZYPCZAK-JANKUN \\ Urology Department, The University of Toledo, Toledo, United States of America
}

\begin{abstract}
Proteolytic and antiproteolytic enzymes play a critical role in the physiology and pathology of different stages of human life. One of the important members of the proteolytic family is the plasminogen activation system (PAS), which includes several elements crucial for this review: the $50 \mathrm{kDa}$ glycoprotein plasminogen activator inhibitor 1 (PAI-1) that inhibits tissue-type (tPA) and urokinase-type plasminogen activator ( $\mathrm{PPA}$ ). These two convert plasminogen into its active form named plasmin that can lyse a broad spectrum of proteins. Urokinase receptor $(u P A R)$ is the binding site of $u P A$. This glycoprotein on the cell surface facilitates urokinase activation of plasminogen, creating high proteolytic activity close to the cell surface. PAS activities have been reported to predict the outcome of kidney transplants. However, reports on expression of PAS in kidney transplants seem to be controversial. On the one hand there are reports that impaired proteolytic activity leads to induction of chronic allograft nephropathy, while on the other hand treatment with UPA and tPA can restore function of acute renal transplants. In this comprehensive review we describe the complexity of the PAS as well as biological effects of the PAS on renal allografts, and provide a possible explanation of the reported controversy.
\end{abstract}

Key words: kidney transplantation, plasminogen, urokinase, tPA.

(Centr Eur Immunol 2018; 43 (2): 222-230)

\section{Introduction}

Proteolytic and antiproteolytic enzymes play a critical role in the physiology and pathology of different stages of human life [1-4]. One of the important members of the proteolytic family is the plasminogen activation system (PAS) [5]. The PAS includes several elements crucial for this review.

Plasminogen is a proenzyme that is activated into plasmin by cleavage via urokinase plasminogen activator (uPA) or tissue plasminogen activator (tPA). Plasmin is a key enzyme in the mechanism responsible for tissue remodeling [6]. It is a strong proteolytic enzyme that digests proteins of connective tissue, basement membranes and blood clots. Additionally, it activates other latent proteolytic enzymes such as procollagenase into collagenase.

Although uPA and tPA both activate plasminogen to plasmin, their proteolytic activity takes place in different tissue environments. uPA is engaged in pericellular proteolysis during tissue remodeling, wound healing, and cell migration. Expression of uPA can occur under a variety of physiologic and pathologic conditions. One example is during malignancy, when uPA causes tissue degradation which facilitates organ invasion and contributes to metastasis [7]. tPA, on the other hand, is mainly involved in intravascular thrombolysis.

Urokinase receptor (uPAR), also known as CD87 (cluster of differentiation 87), is the binding site of UPA. It is a glycoprotein on the cell surface that facilitates urokinase activation of plasminogen. High numbers of uPA receptors on the cell surface create high proteolytic activity in the vicinity of cells $[8,9]$. Soluble urokinase-type plasminogen activator receptor (suPAR) results from the cleavage and release of membrane anchored uPA receptors. suPAR concentration positively correlates with activation of the immune system. It is present in plasma, urine, blood, serum, and cerebrospinal fluid [10, 11].

Inhibitors of plasminogen activators are also part of the plasminogen activation system (PAS). There are a few known proteins that inhibit uPA and tPA. The most relevant is plasminogen activator inhibitor type 1 (PAI-1), also known as the endothelial plasminogen activator inhibitor. This is encoded by the SERPINE1 gene in humans. Additionally, plasminogen activator inhibitor type 2 (PAI-2) is

Correspondence: Prof. Jerzy Jankun, Urology Department, The University of Toledo, 3000 Arlington, 43614 Toledo, United States of America, e-mail: jerzy.jankun@utoledo.edu

Submitted: 28.03.2017; Accepted: 27.04.2017 
secreted by the placenta during pregnancy. A third protein with plasminogen activator inhibition activity is the protease Nexin. PAI-1 exists in three different forms: active, nonactivelatent, and nonactive-cleaved [12, 13]. In addition to inhibiting plasminogen activation, PAI-1 also interacts with the adhesive glycoprotein vitronectin, which plays a role in tissue remodeling and metastasis. In conjunction with vitronectin, it amplifies the motility of cancer cells, facilitating metastasis. However, PAI-1 in high concentrations inhibits tPA, uPA and the activity of matrix metalloproteinases. These play a crucial role in the invasion of malignant cells, reducing angiogenesis, tumor growth and metastasis [14-16].

The wild-type PAI-1 gene located on chromosome 7 (7q21.3-q22) in the promoter region contains a region of five consecutive guanosine $(\mathrm{G})$ residues at $675 \mathrm{bp}$ upstream from the mRNA initiation point. However, genetic polymorphism has been identified where one allele has a sequence of five guanosines $(4 \mathrm{G} / 5 \mathrm{G})$ and another has four (4G/4G), causing a significant increase of PAI-1 activity. Both the $4 \mathrm{G}$ and $5 \mathrm{G}$ alleles have a binding site for an activator of transcription, but the $4 \mathrm{G}$ allele does not have an additional binding site for a repressor that $5 \mathrm{G}$ does, thus leading to higher transcription rates and higher PAI-1 activity in $4 \mathrm{G} / 5 \mathrm{G}$ and $4 \mathrm{G} / 4 \mathrm{G}$ mutants $[17,18]$.

\section{Renal allograft rejection and plasminogen activation system}

Thrombosis in kidneys undergoing vascular rejection and those with various other diseases strongly support the thesis that an imbalance of the urokinase plasminogen activator system (uPAS) is involved in kidney ailments. Indeed, components of the uPAS are present in healthy and diseased kidneys, as demonstrated by histological staining and secretion in urine $[7,8,19,20]$.

\section{Plasminogen activators in kidney transplants}

Thrombosis in a transplanted kidney is a dangerous complication that frequently leads to graft loss [21]. Urokinase and tPA exhibit an affinity for blood clots to direct and concentrate the thrombolytic agent at the site of pathologic thrombi. These agents are used for prevention and therapy of acute thrombosis, but surprisingly are reported only by a few papers on renal transplantation.

Killewich et al. described a case of a 69-year-old man who underwent a cadaveric renal transplantation. He was subsequently admitted with caval, iliac, and renal allograft vein thrombosis. The patient was oliguric and renal function deteriorated rapidly. Urokinase thrombolytic therapy was initiated and lysis of the thrombus was noted within 72 hours. The patient's renal function improved, and his allograft was salvaged [22]. Rouviere et al. studied fibrinolysis as a treatment of acute renal transplant artery thrombosis. In the study, four patients underwent intra-arterial fibrinolysis of immediate post-transplant arterial thrombosis (tPA in one patient and uPA in three patients). In two of the patients, the graft artery was successfully revascularized and dialysis was avoided. One patient was successfully revascularized but had to undergo dialysis briefly. One patient was unsuccessfully revascularized. The authors of this study concluded that fibrinolysis by either tPA or uPA may be useful in salvage of allografts after arterial occlusion [21].

Roelofs et al. evaluated the expression of uPA in renal parenchyma during acute renal allograft rejection. Immunostaining and in situ hybridization for uPA were performed on renal biopsies. Biopsies of viable allografts showed no expression of uPA by immunostaining. However, uPA was detected in low titers in tubular epithelial cells by in situ hybridization. The author also found up-regulation of uPA in biopsies of rejected allografts while lymphocytes and tubular epithelial cells showed uPA expression. Urokinase was also heavily expressed within the vessel walls during vascular rejection [23].

The function of the fibrinolytic system is to dissolve blood clots, and the primary enzyme is tPA. Low levels of tPA result in hypofibrinolysis, which is seen in those with chronic azotemia as well as renal transplant recipients. Opatrny et al. reported that fibrinolysis defects may contribute to development of atherosclerosis resulting in chronic dysfunction of the renal transplant. They emphasize that the exact role of hypofibrinolysis in renal dysfunction is unclear and requires further research [18]. Perkowska et al. evaluated the effects of chronic rejection on fibrinolytic enzymes in the plasma of kidney recipients. They studied the concentration of antigen and the activity of tPA and uPA in renal allograft recipients. Sixty-four patients with cadaveric kidney transplants were matched with thirty healthy blood donors. Thirty-eight patients had stable graft function for six months or more and 26 recipients had biopsy-proven chronic rejection of the allograft. They found statistically significantly higher tPA activity in the plasma of rejected allografts in comparison to the control group [24].

Chronic allograft nephropathy (CAN) results in reduction of the glomerular filtration rate (GFR) as a result of tubular atrophy, interstitial fibrosis, and fibrous intimal thickening of the small arteries. Therefore, Yamaguchi et al. examined the level of uPA released from peripheral $\mathrm{T}$ lymphocytes in transplant patients with CAN as compared to controls. Lymphocytes from patients with CAN had a significantly lower UPA release secondary to the V1-receptor antagonist and desmopressin (dDAVP) than those from the other groups. They suggested that a reduction in uPA release from human peripheral blood lymphocytes by vasopressin-related (AVP) peptides could be potentially 
implicated in the pathology of chronic allograft nephropathy [25].

\section{uPAR in kidney transplants}

The urokinase plasminogen activator and its receptor focus their proteolytic activity in the proximity of the cells expressing them. Binding to the cell surface is performed by the glycophosphatidylinositol (GPI) anchor of uPAR, making it available for uPA binding. When uPA is bound to the receptor, it is cleaved at the GPI anchor, forming suPAR [26-28].

Roelofs et al. investigated the local and systemic release of UPAR and its expression in renal tissues during acute renal allograft rejection. The authors collected blood, urine, and renal biopsy samples from 33 people diagnosed with acute allograft rejection. As controls, the authors used blood and urine samples from 14 patients without rejection and 10 healthy volunteers. In the urine and blood samples, the UPAR amount was determined by ELISA. Immunostaining and in situ hybridization were performed on the tissue samples. The authors found that the levels of UPAR in serum and urine were low in the samples of healthy volunteers, enhanced in the nonrejecting allograft recipients, and the highest in transplant recipients with rejection. Moreover, the urine and serum levels of UPAR correlated with the renal function. Nonrejected biopsies showed no expression of uPAR by immunostaining and in situ hybridization but up-regulation of UPAR in rejection biopsies. Furthermore, lymphocytes and tubular epithelial cells during acute renal allograft rejection showed UPAR expression [23].

In general, patients with focal segmental glomerulosclerosis (FSGS) have increased suPAR levels, which negatively correlate with estimated glomerular filtration rate [29]. Harita et al. explored the possible involvement of suPAR in FSGS pathogenesis by analyzing expression of suPAR in serum of 17 patients with FSGS and compared them to patients with steroid-sensitive nephrotic syndrome, chronic glomerulonephritis, or non-glomerular kidney diseases. They found that serum suPAR amounts in patients with FSGS were higher than those in patients with steroid-sensitive nephrotic syndrome or chronic glomerulonephritis. However, levels were not higher than in patients with non-glomerular kidney diseases. Also, amounts of suPAR negatively correlated with estimated glomerular filtration rate. In the conclusion of their study they stated that elevated suPAR levels in FSGS patients were attributed mainly to decreased glomerular filtration [28].

After kidney transplantation, recurrence of FSGS is a major problem. Mujtaba et al. tested 28 pre-transplant patients with a history of idiopathic FSGS for suPAR, which was used as a biomarker for risk of recurrence of FSGS. Eleven patients with polycystic kidney disease (PKD) were used as controls. The authors found that 12 patients had biopsy-proven post-transplant FSGS recurrence at one and a half months. They also determined that there was no difference in the pre-transplant suPAR levels of FSGS patients compared to patients with PKD. In addition, serum suPAR levels in patients with FSGS recurrence were not different than in those without recurrence [30]. In another study, Franco Palacios et al. evaluated serum and urine levels of suPAR in order to determine its prognostic value. Eighty-six kidney transplant recipients were used prior to transplantation and ten healthy individuals were used as controls. The authors identified the following kidney pathology in transplantation candidates: FSGS, diabetic nephropathy, membranous nephropathy, igA nephropathy, and autosomal dominant polycystic kidney disease. They found elevation of suPAR in the serum and urine in transplant candidates with advanced renal disease. Increased serum and urine suPAR concentration was also directly correlated with proteinuria and albuminuria. The authors also noted that suPAR concentration in the urine was elevated in cases of recurrent FSGS as compared with all other end-stage renal disease. The authors concluded that serum suPAR is elevated in a handful of advanced renal diseases but urinary suPAR appears to be higher in cases of FSGS, which could allow it to potentially be exploited as a target in the therapy of the disease [31].

In another study, Bock et al. investigated suPAR concentration in children with FSGS. The authors examined serum samples from 99 individuals between 1 and 21 years of age. One third of the patients in the study were kidney transplant recipients. The authors noted that there were statistically significantly higher suPAR levels in children with nonglomerular kidney disease when compared to those with FSGS. Although some aspects of the study design remained in question, the authors concluded that circulating suPAR was unlikely the leading cause of childhood idiopathic FSGS [32].

Tang et al. analyzed the expression of uPAR in samples of ten chronically rejected human kidneys and ten normal kidneys using Northern blot analysis. The expression of uPAR mRNA was elevated in chronically rejected kidney samples. Immunohistochemical staining in normal kidneys showed moderate to intense UPAR presence in proximal tubules, and moderate presence in the distal tubules. A similar staining pattern was found in the distal and proximal tubules of rejected kidneys. In addition, there was positive staining for uPAR in the mesangial cells in the glomeruli of rejected kidneys. The normal kidneys showed no reactivity in these regions [33].

\section{PAI-1 in renal transplants}

In light of the influence of the $4 \mathrm{G} / 5 \mathrm{G}$ polymorphism on PAI-1 plasma activity, Rerolle et al. probed the connection between donor and recipient PAI-1 polymorphism and kidney allograft survival. The authors determined the 
PAI-1 genotype in 304 donors and 337 matching recipients and subsequently tested for $4 \mathrm{G} / 4 \mathrm{G}$ (the highest PAI-1 activity) in addition to other genotypes. The authors found that donor and recipient genotype did not affect the PAI1 plasma concentration in recipients after transplantation. However, decreased graft survival was noted in the $4 \mathrm{G} / 4 \mathrm{G}$ donor group, suggesting that 4G/4G PAI-1 genotype is an independent risk factor for graft loss. The authors stated that further prospective studies were needed to confirm these results [34].

In another study, Tang et al. analyzed PAI-1 in samples of chronically rejected human kidneys and normal kidneys by Northern blot analysis and immunohistochemistry. In Northern blot analysis, the expression of PAI1 mRNA was increased in chronically rejected kidney samples as compared with normal controls [33]. Another study from the Vanderbilt and Nashville Medical Center analyzed renal biopsies of allografts for fibrosis. All cases were scored for severity of fibrosis in the renal vasculature, glomeruli and interstitium. PAI-1 was assessed on a scale of 0-3 in 82 patients. The authors found that glomerular PAI-1 staining scores were higher in chronic allograft nephropathy (CAN) than in controls and biopsies of transplanted kidneys without CAN. In conclusion, the study determined that PAI-1 was higher in CAN than in non-scarred native or transplant controls. Moreover, they speculated that altered matrix metabolism may be involved in the development of CAN [35].

Using cryopreserved lymphocytes or splenocytes as the source of donor DNA from histocompatibility typing Krajewska et al. determined 4G/5G PAI-1 polymorphisms by polymerase chain reaction (PCR). The aim of this study was to determine the association of donor genetic PAI-1 status with long-term graft function. They observed the outcomes of 125 patients for at least 12 months. Contrary to others, the lowest values of glomerular filtration rate (as a measure of graft failure) were in recipients of kidney from donors with homozygous PAI-1 5G polymorphism. They suggested that lower PAI-1 synthesis intensifies proteolysis, leading to decreased long-term graft function [36].

Azarpira et al. studied plasminogen activator inhibitor-1 gene polymorphism in chronic allograft dysfunction. Genotyping were determined by PCR in 127 renal allograft recipients (77 with chronic allograft dysfunction, 50 with normal kidney function) and 50 healthy subjects as controls. They did not observe significant differences between the allelic and genotypic distributions of PAI-1 polymorphisms [37].

Perkowska et al. evaluated the influence of chronic rejection on the concentration of PAI-I in plasma of kidney allograft recipients. From 64 patients who had had cadaveric kidney transplantation 38 had stable graft function for at least six months. Twenty-six of them had biopsy-proven chronic rejection of the kidney transplant. Additionally, they included a control group of 30 healthy blood donors. In kidney transplant recipients they found significantly lower plasma PAI-I activity compared to healthy controls. Between transplant patients, PAI-I plasma activity in chronic graft rejection recipients was significantly higher than in stable kidney function patients [24].

Plasma concentration of PAI-1 is genetically governed by a polymorphism in the promoter region of two alleles, $4 \mathrm{G}$ and $5 \mathrm{G}$, with the highest concentrations in subjects homozygous for the $4 \mathrm{G}$ allele than others $(5 \mathrm{G} / 5 \mathrm{G}$ and 4G/5G). Chow et al. investigated PAI-1 4G/5G-promoter genotype polymorphism among 130 kidney transplant patients over 79 months. They found no correlation between the primary event and PAI-1 genotype among the entire group. However, among recipients having the highest PAI-1 concentration (homozygous 4G) those with prior acute rejection episodes had a higher risk of progressive renal damage. They suggested that PAI-1 promoter polymorphisms could possibly be an essential factor of renal response to rejection [38].

The microdissected glomeruli of 23 kidneys of transplant patients were biopsied a few times during follow-up to

Table 1. Plasma concentration half-life and site of synthesis of plasminogen activation system [45, 61-65]

\begin{tabular}{|c|c|c|c|}
\hline & Plasma concentration (ng/ml) & Plasma half-life & Predominant site of synthesis \\
\hline Plasminogen & 200 & 1.8-2.7 days & liver \\
\hline Plasmin & undetectable & very short & - \\
\hline PAI-1 & 0.02 & 2 hours & vascular endothelium, liver, adipocytes \\
\hline PAI-2 & $<0.005$ & - & placenta, macrophages \\
\hline uPA & 0.008 & $\begin{array}{l}\text { sc-uPA } 7 \text { minutes } \\
\text { tc-uPA } 60 \text { minutes }\end{array}$ & kidney, other organs and a variety of tumors \\
\hline suPAR & 2.6 & very short & $\begin{array}{c}\text { monocytes, macrophages, fibroblasts, endothelial } \\
\text { cells and a variety of } \\
\text { tumors }\end{array}$ \\
\hline $\mathrm{tPA}$ & 0.005 & 5 minutes & vascular endothelium \\
\hline
\end{tabular}

Sc-uPA - single chain urokinase, tc-uPA - two chain urokinase 
five years. The glomeruli of three patients after nephrectomy suffering from cancer were considered as controls. The authors investigated mRNA expression of the PAI-1 by reverse transcription polymerase chain reaction. They observed substantial up-regulation of PAI-1 mRNA in acute rejection when compared to control kidneys (presumably due to tissue availability). They concluded that a positive correlation exist between the degradation of renal function and the mRNA level of PAI-1 and that glomerular PAI-1 mRNA may be predictive of long-term renal graft function [39].

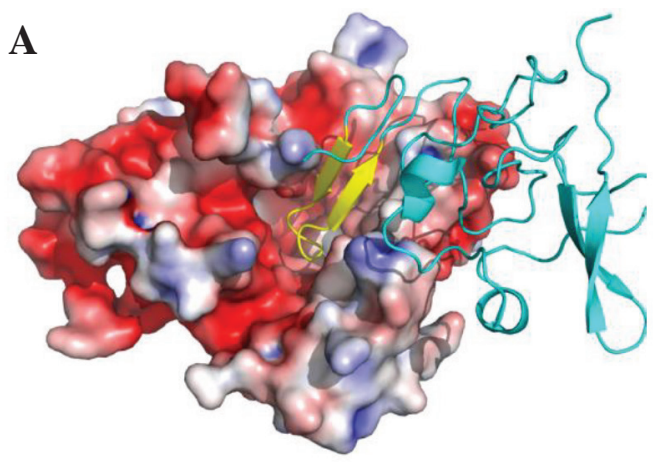

C

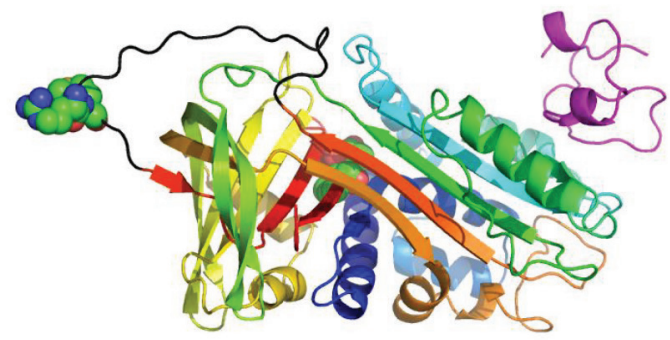

E

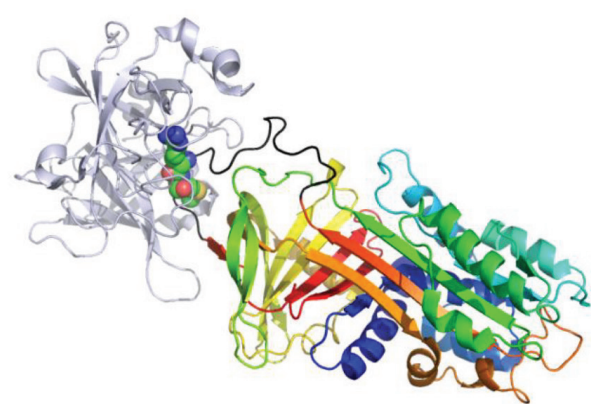

B

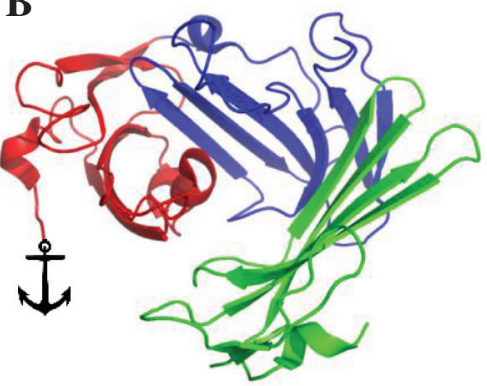

D

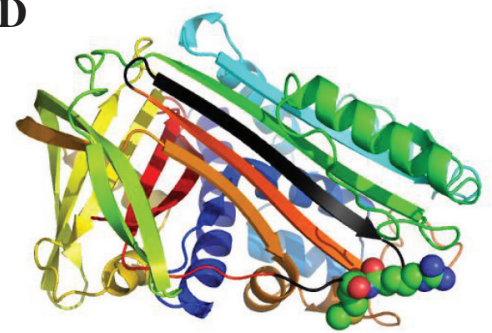

$\mathbf{F}$

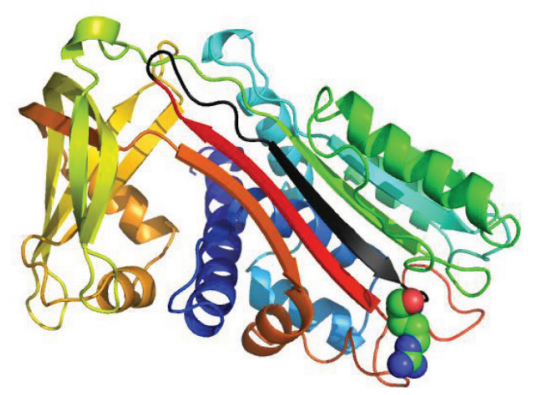

Fig. 1. uPAR A) shown as surface colored by electrostatic surface representation (red negative, blue positive), ATF of uPA shown as cartoon colored in cyan binds to the central cavity of suPAR and the $\Omega$-loop of uPA that is primarily responsible for the high-affinity binding (Cys19-Cys31 colored in yellow, 3U73). B) uPAR domains (3U73): residues 1-93 domain DI shown in green, residues 94-191 domain DII shown in blue, residues 192-277 domain DIII shown in red, uPAR is attached to cell surface by GPI anchor (glycosylphosphatidylinositol) D-III domain [66]. Ribbon models of different forms of PAI-1 colored as "rainbow", residues 353-373 of reactive center loop (RCL) shown in black, active site residues 369, 370 shown as spheres colored by atoms (carbon: green, nitrogen: blue, sulfur: yellow, oxygen: red). All residues numbered as in 3R4L PAI-1 VLHL [67]. C) vitronectin fragment shown in magenta, tPA ribbon model shown in gray. In active conformation PAI-1's C) RCL is extended from the main body of the protein molecule with active site P1'-P1 (model: 3R4L VLHL PAI-1 [67]), vitronectin stabilizes active form of PAI-1 (vitronectin model fragment from 1OC0 PAI-1 [68]). Inherent conformational instability of active PAI-1 leads to rapid conversion to a latent, inactive structure. In latent conformation D) this loop is inserted between A3 and A5 strands of PAI-1, turning into strand A4 and is not available for reaction with PAI-1 substrates (1LJ5 latent [69]). Active PAI-1 binds uPA or tPA as shown in E) (PAI-1/tPA complex model 5BRR [70]), it is cleaved at Arg369 and Met370, and slowly dissociate forming cleaved PAI-1 F) structurally similar to latent form of PAI-1 (9PAI cleaved [71, 72]) 


\section{Discussion}

Reports on expression of uPA and tPA in kidney transplants seem to be controversial. On the one hand there are reports that impaired proteolytic activity leads to induction of chronic allograft nephropathy (CAN), defined as a decline in glomerular filtration rate (GFR) caused by tubular atrophy and interstitial fibrosis, often with fibrous thickening of the innermost lining of the small arteries [25]. On the other hand, treatment with uPA and tPA can restore function of acute renal transplant after artery thrombosis [21, 22]. To make the matter more confusing, in kidney transplant recipients plasma tPA activity is higher than in healthy controls [24]. An additional complicating factor in assessment of uPA function in kidney transplants is the diversity of analytical tools used. For example, some papers report the antigen level in kidney, while some report plasminogen activator activity in blood or urine [23-25, 31, 40, 41].

Assessment of the predictive role of UPAR or suPAR in kidney rejection is slightly clearer than function of plasminogen activators as UPAR and suPAR are elevated in most kidney diseases and kidney transplant rejection. However, formation of suPAR is a result of cleavage at the GPI anchor of UPAR at the D-III domain and is catalyzed by various enzymes. It can also occur at the linker region and between DI and DII domains. The suPAR formed by cleavage may thus include domains DI-II-III (suPARI-III), DII-III (suPARII-III) or DI (suPARI) (Fig. $1 \mathrm{a}, \mathrm{b}$ ). Only suPARI-III binds vitronectin and UPA and it is able to interact with integrins and affects intracellular processes. Cleaved fragments DIII or DII-III can either be bound to the cell membrane or be soluble $[42,43]$. The role of the splice variants is largely unknown but is clearly not proteolytic [43]. We were not able to find a study that discriminates between all these forms, making it very difficult to establish the causative role of the receptor.

PAI-1 is elevated in kidney rejection as well as the other elements of the plasminogen activation system. However, as can be seen in Fig. 1, it can exist in four distinctly different forms. Only the active form (Fig. $1 \mathrm{c}$ ) can inactivate tPA or uPA, while the others are anti-proteolytic inactive forms. Active PAI-1 is conformationally instable and converts rapidly to a latent (Fig. $1 \mathrm{~d}$ ), inactive structure with a half-life of two hours [7]. Serpins including PAI-1 form complexes with target proteases (tPA, uPA shown in Fig. 1 e) that later dissociate slowly, having been cleaved at the scissile bond (P1 and $\mathrm{P} 1^{\prime}$ ) and then fold into a highly stable inactive state (Fig. $1 \mathrm{f}$ ) in which the residues $\mathrm{P} 1, \mathrm{P} 1^{\prime}$ of the active site are separated by a wide gap [44]. Unfortunately, none of the reviewed studies were able to determine presence/concentration of different forms of PAI-1, but different forms can have different modes of action. In general, the concentration (referred to in many publications as the level) of the molecule does not necessarily reflect its activity and in the case of such a molecule as PAI-1 could be very misleading.
While the level of the compound reflects its pharmacokinetics, its activity affects pharmacodynamic properties, which cannot be evaluated for the inactive protein.

The structure and function of the plasminogen activation system as well as the serine protein family to which PAS belongs have been characterized and are well understood [45]. If the upregulation of PAS in kidney transplants is related solely to abnormal proteolysis it can be controlled by small molecular inhibitors leading to novel therapeutic interventions. For example, amidine inhibitors can inhibit uPA and/ or tPA by binding to their active sites. High specificity or affinity were successfully achieved by alternating the molecular structure of existing inhibitors [46, 47]. The other option is to use one of the recombinant PAI-1 engineered to extend its activity (from a half-life of $2 \mathrm{~h}$ to over $700 \mathrm{~h}$ ), which opens the possibility of therapeutic use [48].

Wang et al. used a large library of chemicals (called the ZING library) to dock them in silico to the uPA binding pocket of UPAR. They identified 127 derivatives that share the core structure of the parental chemicals having potential uPAR inhibitory activity. These chemicals were evaluated by ELISA for their inhibitory activity toward the UPAR binding site of the uPA amino terminal fragment. Fifteen compounds had inhibitory activity of $\leq 50 \mu \mathrm{M}$ [49]. The other approach was to generate a uPA-derived uPA receptor binding sequence, uPA (AA 19-31), in chicken cystatin. The authors reported that this construct competed with binding of uPA to the cell surface associated UPAR expressed on human U937 cells [50].

Inhibition of PAI-1 can be achieved both by inhibitory antibody or small molecule inhibitors [51]. The inhibitory antibodies inactivate PAI-1 by preventing formation of the Michaelis complex between the substrate (uPA or tPA) and PAI-1 [52]. Additionally, acceleration of the transition from the active to the latent form or by inducing turnover of the PAI-1 protease complex has been postulated as well [53-56]. Small molecule inhibitors such us AR-H029953XX [57] and PAI-039 [58] bind to the hydrophobic cleft region in the proximity of $\alpha$-helices D, E and $\beta$-strand $1 \mathrm{~A}$, critical for the interaction between PAI-1 and its substrate. Another binding site was proposed for the PAI-749 small molecule inhibitor that prevents formation of the complex between PAI-1 and plasminogen activators [59]. Also, our study revealed that the isolated theaflavins from black tea (theaflavin- 3 '-gallate, theaflavin-3,3'-digallate) were potent inhibitors of PAI-1 [60]. From computer molecular modeling of complex formation, we identified the most likely place of binding at the proximity of Arg346-Met347 (P1, P1'), i.e. at the active site of PAI-1 [54, 60].

\section{Conclusions}

All these examples reveal that modulation of the PAS is possible at the proteolysis level. Moreover, further progress concerning the function of the plasminogen activation 
system as a prognostic marker and therapeutic target in kidney transplantation will depend not only on understanding the role played by each member but also on interaction between them regulating net proteolytic activity. Equally critical will be understanding where elements of the PAS are expressed (circulation, or kidney itself) and how they affect kidney allograft. Another very important factor is understanding the role of PAS members that are not proteolytically active (PAI-1 latent or cleaved forms, DI, DII, DII suPAR) and were not measured or detected in the studies described in the reviewed papers. Our understanding of the role played by PAS in kidney transplantation, other than proteolysis, is far from complete and should be investigated further to allow more substantial conclusions.

\section{The authors declare no conflict of interest.}

\section{References}

1. Heidland A, Ling H, Vamvakas S, et al. (1996): Impaired proteolytic activity as a potential cause of progressive renal disease. Miner Electrolyte Metab 22: 157-161.

2. Skrzydlewska E, Sulkowska M, Koda M, et al. (2005): Proteolytic-antiproteolytic balance and its regulation in carcinogenesis. World J Gastroenterol 11: 1251-1266.

3. Turner AJ, Nalivaeva NN (2007): New insights into the roles of metalloproteinases in neurodegeneration and neuroprotection. Int Rev Neurobiol 82: 113-135.

4. Vaughan DE (2002): Angiotensin and vascular fibrinolytic balance. Am J Hypertens 15: 3S-8S.

5. Draxler DF, Medcalf RL (2015): The fibrinolytic system-more than fibrinolysis? Transfus Med Rev 29: 102-109.

6. Chorostowska-Wynimko J, Skrzypczak-Jankun E, Jankun J (2004): Plasminogen activator inhibitor type-1: its structure, biological activity and role in tumorigenesis (Review). Int J Mol Med 13: 759-766.

7. Jankun J, Skrzypczak-Jankun E (2009): Yin and yang of the plasminogen activator inhibitor. Pol Arch Med Wewn 119: 410-417.

8. Blasi F, Sidenius N (2010): The urokinase receptor: focused cell surface proteolysis, cell adhesion and signaling. FEBS Lett 584: 1923-1930.

9. Qiu D, Owen K, Gray K, et al. (2007): Roles and regulation of membrane-associated serine proteases. Biochem Soc Trans 35: 583-587.

10. Del Rosso M, Margheri F, Serrati S, et al. (2011): The urokinase receptor system, a key regulator at the intersection between inflammation, immunity, and coagulation. Curr Pharm Des 17: 1924-1943.

11. Mustjoki S, Sidenius N, Sier CF, et al. (2000): Soluble urokinase receptor levels correlate with number of circulating tumor cells in acute myeloid leukemia and decrease rapidly during chemotherapy. Cancer Res 60: 7126-7132.

12. Aso Y (2007): Plasminogen activator inhibitor (PAI)-1 in vascular inflammation and thrombosis. Front Biosci 12: 29572966.

13. Vaughan DE (2005): PAI-1 and atherothrombosis. J Thromb Haemost 3: 1879-1883.

14. Binder BR, Mihaly J (2008): The plasminogen activator inhibitor "paradox" in cancer. Immunol Lett 118: 116-124.
15. Diebold I, Kraicun D, Bonello S, et al. (2008): The 'PAI-1 paradox' in vascular remodeling. Thromb Haemost 100: 984991.

16. Kobalka AJ, Keck RW, Jankun J (2015): Synergistic anticancer activity of biologicals from green and black tea on DU 145 human prostate cancer cells. Cent Eur J Immunol 40: 1-4.

17. Tsantes AE, Nikolopoulos GK, Bagos PG, et al. (2008): The effect of the plasminogen activator inhibitor- $14 \mathrm{G} / 5 \mathrm{G}$ polymorphism on the thrombotic risk. Thromb Res 122: 736-742.

18. Burzotta F, Di Castelnuovo A, Amore C, et al. (1998): [The role of $4 \mathrm{G} / 5 \mathrm{G}$ polymorphism in the regulation of plasma levels of PAI-1: a model of interaction between genetic and environmental factors]. Cardiologia 43: 83-88.

19. Opatrny K Jr., Zemanova P, Opatrna S, et al. (2002): Fibrinolysis in chronic renal failure, dialysis and renal transplantation. Ann Transplant 7: 34-43.

20. Wu CZ, Chang LC, Lin YF, et al. (2015): Urokinase plasminogen activator receptor and its soluble form in common biopsy-proven kidney diseases and in staging of diabetic nephropathy. Clin Biochem 48: 1324-1329.

21. Rouviere O, Berger P, Beziat C, et al. (2002): Acute thrombosis of renal transplant artery: graft salvage by means of intra-arterial fibrinolysis. Transplantation 73: 403-409.

22. Killewich LA, Pais SO, Sandager G, et al. (1995): Salvage of renal allograft function and lower extremity venous patency with thrombolytic therapy: case report and review of the literature. J Vasc Surg 21: 691-696.

23. Roelofs JJ, Rowshani AT, van den Berg JG, et al. (2003): Expression of urokinase plasminogen activator and its receptor during acute renal allograft rejection. Kidney Int 64: 1845-1853.

24. Perkowska A, Elhasade A, Durlik M, et al. (2002): The effect of chronic allograft rejection on plasma regulators of fibrinolysis. Ann Transplant 7: 44-51.

25. Yamaguchi Y, Suzuki T, Arita S, et al. (2005): Possible involvement of urokinase-type plasminogen activator release from human peripheral blood lymphocytes in the pathophysiology of chronic allograft nephropathy. Transplant Proc 37: 4276-4281.

26. Huang M, Mazar AP, Parry G, et al. (2005): Crystallization of soluble urokinase receptor (suPAR) in complex with urokinase amino-terminal fragment (1-143). Acta Crystallogr D Biol Crystallogr 61: 697-700.

27. Hoyer-Hansen G, Pessara U, Holm A, et al. (2001): Urokinase-catalysed cleavage of the urokinase receptor requires an intact glycolipid anchor. Biochem J 358: 673-679.

28. Ploug M, Ronne E, Behrendt N, et al. (1991): Cellular receptor for urokinase plasminogen activator. Carboxyl-terminal processing and membrane anchoring by glycosyl-phosphatidylinositol. J Biol Chem 266: 1926-1933.

29. Harita Y, Ishizuka K, Tanego A, et al. (2014): Decreased glomerular filtration as the primary factor of elevated circulating suPAR levels in focal segmental glomerulosclerosis. Pediatr Nephrol 29: 1553-1560.

30. Mujtaba MA, Sharfuddin AA, Book BL, et al. (2015): Pre-transplant angiotensin receptor II type 1 antibodies and risk of post-transplant focal segmental glomerulosclerosis recurrence. Clin Transplant 29: 606-611.

31. Franco Palacios CR, Lieske JC, Wadei HM, et al. (2013): Urine but not serum soluble urokinase receptor (suPAR) may identify cases of recurrent FSGS in kidney transplant candidates. Transplantation 96: 394-399.

32. Bock ME, Price HE, Gallon L, et al. (2013): Serum soluble urokinase-type plasminogen activator receptor levels and idio- 
pathic FSGS in children: a single-center report. Clin J Am Soc Nephrol 8: 1304-1311.

33. Tang WH, Friess H, di Mola FF, et al. (1998): Activation of the serine proteinase system in chronic kidney rejection. Transplantation 65: 1628-1634.

34. Rerolle JP, Munteanu E, Drouet M, et al. (2008): PAI-1 donor polymorphism influences long-term kidney graft survival. Nephrol Dial Transplant 23: 3325-3332.

35. Revelo MP, Federspiel C, Helderman H, et al. (2005): Chronic allograft nephropathy: expression and localization of PAI-1 and PPAR-gamma. Nephrol Dial Transplant 20: 2812-2819.

36. Krajewska M, Koscielska-Kasprzak K, Weyde W, et al. (2009): Impact of donor-dependent genetic factors on longterm renal graft function. Transplant Proc 41: 2978-2980.

37. Azarpira N, Bagheri M, Raisjalali GA, et al. (2009): Angiotensinogen, angiotensine converting enzyme and plasminogen activator inhibitor-1 gene polymorphism in chronic allograft dysfunction. Mol Biol Rep 36: 909-915.

38. Chow KM, Szeto CC, Szeto CY, et al. (2002): Plasminogen activator inhibitor-1 polymorphism is associated with progressive renal dysfunction after acute rejection in renal transplant recipients. Transplantation 74: 1791-1794.

39. Delarue F, Hertig A, Alberti C, et al. (2001): Prognostic value of plasminogen activator inhibitor type 1 mRNA in microdissected glomeruli from transplanted kidneys. Transplantation 72: 1256-1261.

40. Gueler F, Rong S, Mengel M, et al. (2008): Renal urokinase-type plasminogen activator (uPA) receptor but not uPA deficiency strongly attenuates ischemia reperfusion injury and acute kidney allograft rejection. J Immunol 181: 1179-1189.

41. Malyszko J, Malyszko JS, Pawlak K, et al. (1996): The coagulo-lytic system and endothelial function in cyclosporine-treated kidney allograft recipients. Transplantation 62: 828-830.

42. Blasi F, Carmeliet P (2002): uPAR: a versatile signalling orchestrator. Nat Rev Mol Cell Biol 3: 932-943.

43. Maas RJ, Deegens JK, Wetzels JF (2013): Serum suPAR in patients with FSGS: trash or treasure? Pediatr Nephrol 28: 1041-1048.

44. Abbott GL, Blouse GE, Perron MJ, et al. (2004): 19F NMR studies of plasminogen activator inhibitor-1. Biochemistry 43: 1507-1519.

45. Cesarman-Maus G, Hajjar KA (2005): Molecular mechanisms of fibrinolysis. Br J Haematol 129: 307-321.

46. Katz BA, Sprengeler PA, Luong C, et al. (2001): Engineering inhibitors highly selective for the S1 sites of Ser190 trypsin-like serine protease drug targets. Chem Biol 8: 1107-1121.

47. Zeslawska E, Schweinitz A, Karcher A, et al. (2000): Crystals of the urokinase type plasminogen activator variant beta(c)-uPAin complex with small molecule inhibitors open the way towards structure-based drug design. J Mol Biol 301: 465-475.

48. Chorostowska-Wynimko J, Swiercz R, Skrzypczak-Jankun E, et al. (2003): A novel form of the plasminogen activator inhibitor created by cysteine mutations extends its half-life: relevance to cancer and angiogenesis. Mol Cancer Ther 2: 19-28.

49. Wang F, Eric Knabe W, Li L, et al. (2012): Design, synthesis, biochemical studies, cellular characterization, and structure-based computational studies of small molecules targeting the urokinase receptor. Bioorg Med Chem 20: 4760-4773.

50. Muehlenweg B, Assfalg-Machleidt I, Parrado SG, et al. (2000): A novel type of bifunctional inhibitor directed against proteolytic activity and receptor/ligand interaction. Cystatin with a urokinase receptor binding site. J Biol Chem 275: 33562-33566.
51. Wyganowska-Swiatkowska M, Urbaniak P, Szkaradkiewicz A, et al. (2016): Effects of chlorhexidine, essential oils and herbal medicines (Salvia, Chamomile, Calendula) on human fibroblast in vitro. Cent Eur J Immunol 41: 125-131.

52. Wyganowska-Swiatkowska M, Jankun J (2015): Plasminogen activation system in oral cancer: Relevance in prognosis and therapy (Review). Int J Oncol 47: 16-24.

53. Gorlatova NV, Cale JM, Elokdah H, et al. (2007): Mechanism of inactivation of plasminogen activator inhibitor- 1 by a small molecule inhibitor. J Biol Chem 282: 9288-9296.

54. Jankun J, Al-Senaidy A, Skrzypczak-Jankun E (2012): Can inactivators of plasminogen activator inhibitor alleviate the burden of obesity and diabetes? (Review). Int J Mol Med 29: 3-11.

55. Naessens D, Gils A, Compernolle G, et al. (2003): Elucidation of a novel epitope of a substrate-inducing monoclonal antibody against the serpin PAI-1. J Thromb Haemost 1: 1028-1033.

56. Verhamme I, Kvassman JO, Day D, et al. (1999): Accelerated conversion of human plasminogen activator inhibitor-1 to its latent form by antibody binding. J Biol Chem 274: 1751117517.

57. Egelund R, Einholm AP, Pedersen KE, et al. (2001): A regulatory hydrophobic area in the flexible joint region of plasminogen activator inhibitor-1, defined with fluorescent activity-neutralizing ligands. Ligand-induced serpin polymerization. J Biol Chem 276: 13077-13086.

58. Crandall DL, Elokdah H, Di L, et al. (2004): Characterization and comparative evaluation of a structurally unique PAI-1 inhibitor exhibiting oral in-vivo efficacy. J Thromb Haemost 2: $1422-1428$

59. Gardell SJ, Krueger JA, Antrilli TA, et al. (2007): Neutralization of plasminogen activator inhibitor I (PAI-1) by the synthetic antagonist PAI-749 via a dual mechanism of action. Mol Pharmacol 72: 897-906.

60. Jankun J, Skotnicka M, Lysiak-Szydlowska W, et al. (2011): Diverse inhibition of plasminogen activator inhibitor type 1 by theaflavins of black tea. Int J Mol Med 27: 525-529.

61. Kohler M, Sen S, Miyashita C, et al. (1991): Half-life of single-chain urokinase-type plasminogen activator (scu-PA) and two-chain urokinase-type plasminogen activator (tcu-PA) in patients with acute myocardial infarction. Thromb Res 62: 75-81.

62. Pepperell D, Morel-Kopp MC, Ward C (2014): Clinical Application of Fibrinolytic Assays. In: Fibrinolysis and Thrombolysis, Kolev K (ed.). IntechOpen, Rijeka.

63. Roychoudhury PK, Khaparde SS, Mattiasson B, et al. (2006): Synthesis, regulation and production of urokinase using mammalian cell culture: a comprehensive review. Biotechnol Adv 24: 514-528.

64. Wiman B (2000): The fibrinolytic enzyme system. Basic principles and links to venous and arterial thrombosis. Hematol Oncol Clin North Am 14: 325-338, vii.

65. Wiman B, Hamsten A (1990): The fibrinolytic enzyme system and its role in the etiology of thromboembolic disease. Semin Thromb Hemost 16: 207-216.

66. Barinka C, Parry G, Callahan J, et al. (2006): Structural basis of interaction between urokinase-type plasminogen activator and its receptor. J Mol Biol 363: 482-495.

67. Jankun J, Yang J, Zheng H, et al. (2012): Remarkable extension of PAI-1 half-life surprisingly brings no changes to its structure. Int J Mol Med 29: 61-64.

68. Zhou A, Huntington JA, Pannu NS, et al. (2003): How vitronectin binds PAI-1 to modulate fibrinolysis and cell migration. Nat Struct Biol 10: 541-544. 
69. Stein PE, Baek K (2002): 1.8A Resolution Structure of Latent Plasminogen Activator Inhibitor-1 (PAI-1), doi: 10.2210/ $\mathrm{pdb} 1 \mathrm{LJ} 5 / \mathrm{pdb}$

70. Gong L, Liu M, Zeng T, et al. (2015): Crystal Structure of the Michaelis Complex between Tissue-type Plasminogen Activator and Plasminogen Activators Inhibitor-1. J Biol Chem 290: 25795-25804.

71. Aertgeerts K, De Bondt HL, De Ranter C, et al. (1995): Crystallization and X-ray diffraction data of the cleaved form of plasminogen activator inhibitor-1. Proteins 23: 118-121.

72. Aertgeerts K, De Bondt HL, De Ranter CJ, et al. (1995): Mechanisms contributing to the conformational and functional flexibility of plasminogen activator inhibitor-1. Nat Struct Biol 2: 891-897. 